\title{
A Review of Published Work on the Solidification Control of Steel in Continuous Casting Moulds by Heat Flux Measurement*
}

\author{
By Manfred M. WOLF**
}

\begin{abstract}
Synopsis
With the increasing trend toward high-speed casting, heat flux measurements may be an important tool for monitoring the progress of solidification in the continuous casting mould - particularly if automatic process control is envisaged.

Therefore, published work has been reviewed in order to reveal the dependence of heat flux on operating conditions such as casting speed and the corresponding mould dwell time, mould cooling intensity and mould geometry, mould lubricant, steel temperature and composition.

Furthermore, the relationship between heat flux and shell growth in the mould is explored through the application of a simple function.
\end{abstract}

\section{Introduction}

In the continuous casting of steel, the function of the water cooled copper mould is fundamental to the operational reliability of the process and also for the surface quality of the product. The strand shell formed in the mould (Fig. 1) must be sufficiently thick to safely contain the liquid metal in the subsequent stages. Furthermore, since the mechanical properties of castings are strongly influenced by the solidification conditions, ${ }^{2}$ ) the intensity and uniformity of cooling will affect the extent of defect formation in the strand shell.

To control the solidification in the continuous casting mould, measurement of mould heat fluxbased on the temperature increase of the cooling water - was already considered an effective means in the early years of continuous casting. ${ }^{3,4)}$ There have such heat flux data been used to derive shell growth and shell temperature by analytical or numerical methods. As illustrated by the example in Fig. 2, progress of shell growth can be described by the following parabolic equation:

$$
Y=K t^{0.5}-C \text {. }
$$

In this equation, $K$ is the so-called parabolic solidification constant (" $K$-factor") and varies within a wide range without obvious reasons. The $C$-value in Eq. (1) expresses the initial retardation of shell growth due to effects of steel superheat. ${ }^{7)}$

In actual plant operation, a large scatter in heat flux data can often be observed even with subsequent casts $^{8)}$ thus seeming to indicate that solidification control will be unreliable.

Such scatter may be due to the complex interaction of a multiplicity of factors which have an influence on mould heat flux, i.e., casting speed, mould cooling and geometry, mould level height and mould lubricant, steel temperature and composition. ${ }^{9)}$ Since, for some of these conditions, quantitative relationships with mould heat flux already exist from previous work, such functions will be reviewed in the following.

\section{Operational Conditions Affecting Mould Heat Flux and Shell Growth}

\section{Casting Speed and Dwell Time in Mould}

The effect of casting speed on mould heat flux has already been frequently investigated. ${ }^{10-12)}$ Plotting the mean heat flux (related to mould surface area) as a function of dwell time-considering also mould level height - results in surprisingly close agreement between the various investigations (Fig. 3). These average results can be closely fitted to the following equation:

$$
\bar{H}_{M} \sim 15000 t_{M}^{-0.5}
$$

Therefore not only shell growth (Fig. 2 (b)), but also heat flux appears to follow a parabolic time law. The effects of casting speed and the corresponding dwell time in the mould may be explicable in the following way ${ }^{13)}$ :

(1) At shorter solidification times, the shell is correspondingly thinner (Fig. 2 (b)) and will thus be pressed by the ferrostatic forces more strongly against the mould wall so increasing heat flux.

(2) Shorter dwell times also give higher strand

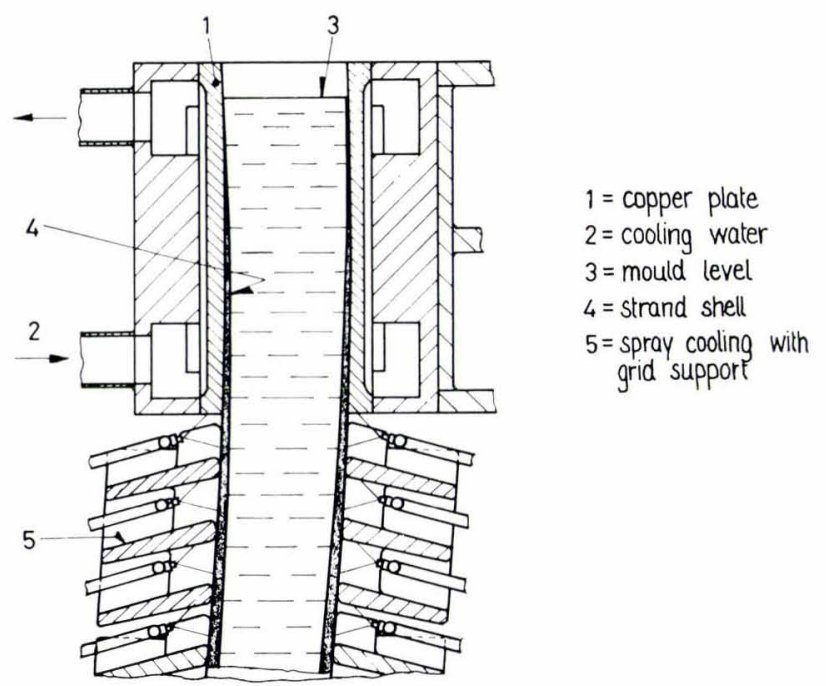

Fig. 1. Formation and growth of the strand shell in the mould, with subsequent spray cooling and grid support. ${ }^{1)}$

* Based on a paper presentation at the 97th ISIJ Meeting, April 1979, The University of Tokyo, Tokyo 113. Manuscript received September 19, 1979.

** CONCAST AG, CH-8027, Zurich, Switzerland. 


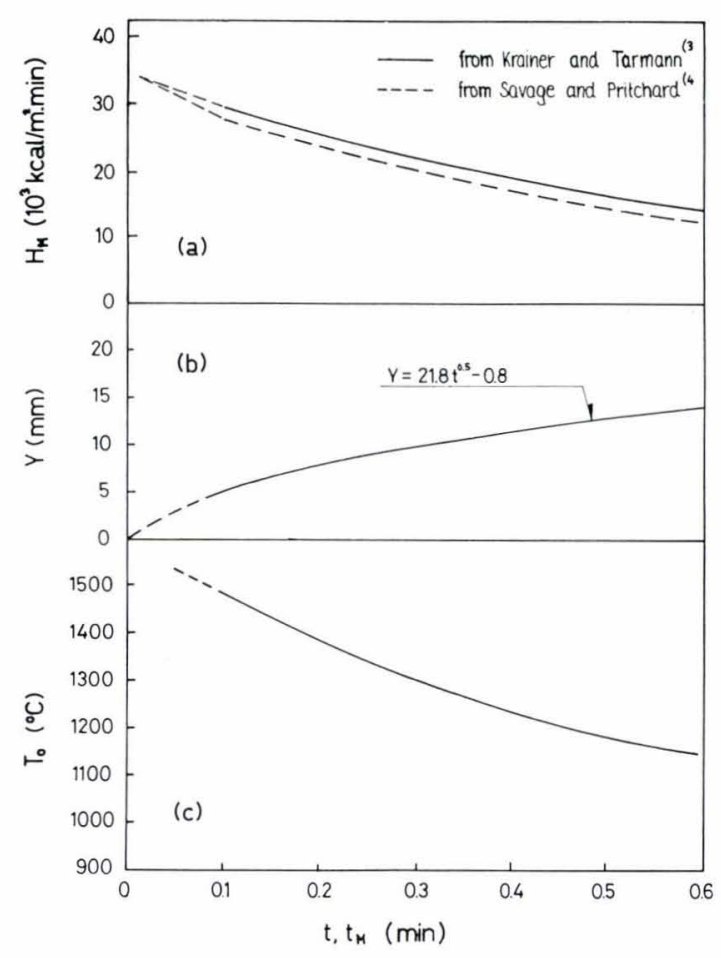

Fig. 2. Dependence of (a) mould heat flux, (b) shell growth and (c) shell surface temperature on dwell time/solidification time; (a) and (b) taken from Ref. 5), (c) from Ref. 6).

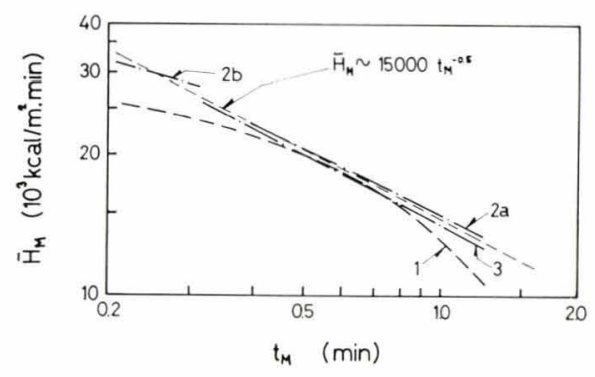

Fig. 3. Dependence of mould heat flux on dwell time from various published reports: curve 1 from Ref. 10), 2 a/b from Ref. 11) and 3 from Ref. 12).

surface temperatures (Fig. 2 (c)), yielding a steeper temperature gradient and enhanced heat flow between strand surface and mould wall.

(3) The higher strand surface temperatures correspond to reduced contraction of the strand shell which again improves heat flux by virtue of better contact with the mould wall.

However, in the above investigations, a wide scatter of at least $\pm 50 \%$ from the mean value was observed. Such deviations can be explained by the influence of other factors which will be attempted below.

\section{Mould Cooling Intensity}

In several investigations, ${ }^{14,15)}$ an increase in mould water velocity clearly decreases the temperature in the mould wall while heat flux remains unchanged. It can thus be reasoned that the gain in heat transfer on the water side is compensated for by a corresponding loss at the strand/mould interface due to enhanced
Table 1. Effect of mould water velocity on heat flux for $0.55 \% \mathrm{C} / 1.7 \%$ Si-spring steel (section $135 \times$ $135 \mathrm{~mm}, V=1.8 \mathrm{~m} / \mathrm{mm}$ ), from Ref. 17).

\begin{tabular}{l|cc} 
Water velocity $(\mathrm{m} / \mathrm{s})$ & 7.6 & 10.0 \\
Mould heat flux $\left(\mathrm{kcal} / \mathrm{m}^{2} \mathrm{~min}\right)$ & 26475 & 18978
\end{tabular}

Table 2. Effect of mould taper on heat flux for $0.50 \% \mathrm{C}$ steel (section $105 \times 105 \mathrm{~mm}, V=1.6 \mathrm{~m} / \mathrm{min}$ ), from Ref. 20).

\begin{tabular}{l|cccc}
\hline Taper $(\% / \mathrm{m})$ & 0 & 1.5 & 2.2 & 2.6 \\
$\begin{array}{c}\text { Mould heat flux } \\
\left(\mathrm{kcal} / \mathrm{m}^{2} \mathrm{~min}\right)\end{array}$ & 15008 & 16704 & 19575 & $*$ \\
\hline
\end{tabular}

* Strand is sticking in the mould.

contraction of the steel shell. ${ }^{16)}$

However, in cases where the steel grade is known to be "shrinkage sensitive", a substantial drop in heat flux may result from increasing mould cooling intensity. Such a case is exemplified for high carbon spring steels in Table 1: an increase in water velocity by $30 \%$ causes a reduction in heat flux by nearly the same extent. ${ }^{17)}$ Similar results, but to a lesser degree, have been also reported from observations made during slab casting of carbon steels. ${ }^{18)}$

An increase of surface defects (transverse depressions and longitudinal face cracks) with higher mould water velocity in the case of austenitic stainless steels has also been observed. ${ }^{19)}$

Therefore, mould cooling intensity can be a factor of considerable influence if the commonly recommended range of mould water velocity between 4 and $6 \mathrm{~m} / \mathrm{s}$ is exceeded. Consequently, rather "soft," cooling should be applied especially in the case of "shrinkage-sensitive" steels. ${ }^{16)}$

\section{Mould Geometry}

It is known from early observations that mould heat flux is significantly improved by tapered mould geometry - especially in the case of small, self-supporting strand sections. Systematic investigation ${ }^{20)}$ has shown that an increase in heat flux up to $30 \%$ can be achieved by tapering the mould but, at the same time, friction also increases considerably (Table 2).

As a result, mould tapers applied to practical operation must safely avoid excessive friction. A $0.9 \% / \mathrm{m}$-taper is frequently applied as a compromise, and heat flux increases between 8 and $15 \%$ are reported in comparison to moulds with parallel walls. ${ }^{9,21)}$ This beneficial effect of mould taper is now widely used in commercial continuous casting operations.

In discussions about the relationship between heat flux and mould geometry, it has been occasionally suggested that the heat flux in a curved mould may be lower than in straight moulds. ${ }^{22)}$ However, no such difference can be found in larger-scale data evaluation. ${ }^{11,12)}$ Rather, there are often observations of heat flux differences between the outer and inner wide face on both curved mould ${ }^{14)}$ as well as straight mould ${ }^{15)}$ casters. Such unevenness in solidification may be primarily attributed to the machine align- 
ment accuracy at the transition from the mould to the top of the secondary cooling zone.

It should also be noted that for slab sections, the heat flux of the narrow faces is generally lower than that for the wide faces ${ }^{23)}$ - despite the taper of the former. The high heat flux of the wide faces can be explained by the intensive shell/mould contact due to the ferrostatic pressure. ${ }^{24)}$

\section{Mould Lubricant}

The effect of mould lubricant on heat flux is still a controversial issue. Some researchers claim that, compared to open pouring with oil as lubricant, closed pouring with the use of mould powders causes a decrease in heat flux by about $30 \%,{ }^{14}$ ) while others find an increase with mould powders of 15 to $20 \%$ over oil lubrication. ${ }^{13)}$

More systematic investigation ${ }^{25)}$ has shown that steels which solidify with a "smooth" shell (i.e., high carbon steels) give, with mould powder, a decrease of about $20 \%$ compared to oil lubrication. On the other hand, steels with a "rough" shell (primarily around $0.12 \% \mathrm{C}$ ) show very little dependence of total heat flux on lubrication medium. Thus, it might be possible that, with very " rough" surfaces, the use of mould powders would improve the strand/mould contact and, hence, also the heat flux.

Considering the effect of mould powder properties on mould heat flux, large variations have been observed, particularly in slab casting, with changing slag viscosity and melting temperature range. ${ }^{11)}$ Since the heat conductivity of liquid slags $(T>$ $1100^{\circ} \mathrm{C}$ ) is largely the same, ${ }^{13}$ ) the effect of mould powders on heat flux may be explicable primarily by changes in the slag film thickness.

As an example the average film thickness calculated from powder consumption has been plotted against casting speed in Fig. 4. At $1.0 \mathrm{~m} / \mathrm{min}$, powder A gives a film thickness of about $0.10 \mathrm{~mm}$ whereas powder B gives a film twice as thick at the same speed. The different film thickness can be primarily attri-

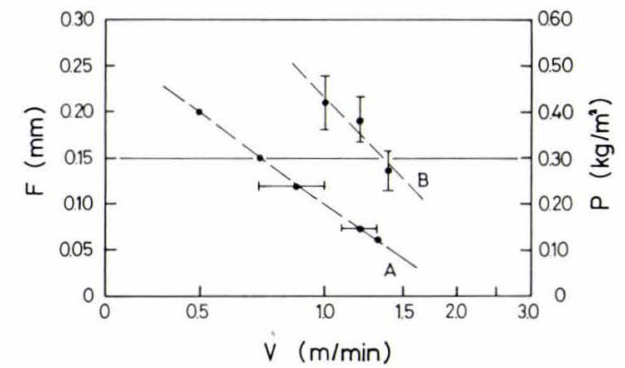

\begin{tabular}{c|ccl|c}
\hline Powder & $\begin{array}{c}\text { Viscosity } \\
\text { at } 1300^{\circ} \mathrm{C} \\
(\text { poise) }\end{array}$ & Steel type & $\begin{array}{c}\text { Section size } \\
(\mathrm{mm})\end{array}$ & Ref. \\
\hline A & 10.0 & various & various & $26)$ \\
B & 2.2 & $0.15 \% \mathrm{C}$ & $220 \times 950 \sim 1300$ & $27)$ \\
\hline
\end{tabular}

Fig. 4. Relation between specific powder consumption resp. calculated average slag film thickness ( $\rho \sim$ $2 \mathrm{t} / \mathrm{m}^{3}$ ) and casting speed for two mould powders. buted to the differences in powder viscosity. ${ }^{28)}$ This relationship is confirmed by relating mould heat flux to powder viscosity. Figure 5 shows a distinct minimum at a certain viscosity level, with heat flux increasing steeply at lower or higher viscosities. This can be explained as follows ${ }^{13)}$ :

(1) If the viscosity is too high, then only a thin or incoherent film is formed due to insufficient slag fluidity.

(2) If the viscosity is too low, then the highly fluid slag film can be interrupted locally by the action of ferrostatic pressure.

Both conditions will lead to high heat flux. Consequently a "stable" slag film can be assumed when heat flux tends toward a minimum, as shown in Fig. 5. Since the product of viscosity and squared casting speed $\left(\eta \cdot V^{2}\right)$ is suggested to be a constant value, ${ }^{29)}$ about 5 poise $\cdot \mathrm{m}^{2} / \mathrm{min}^{2}$ may be characteristic for "stable" conditions in this case, i.e., steels with less than $0.20 \% \mathrm{C}$ and characteristic strand surface temperature (near meniscus) of about $1300^{\circ} \mathrm{C}$. For the powders A and B in Fig. 4, this would give an optimum casting speed of 0.7 and $1.5 \mathrm{~m} / \mathrm{min}$ respectively corresponding to an optimum film thickness of about $0.15 \mathrm{~mm}$ (or $0.30 \mathrm{~kg} / \mathrm{m}^{2}$ ) which agrees with plant observation.

In the context of selecting the optimum casting speed range for a given mould powder, additional support can be gained by mould friction measurements. ${ }^{30)}$ For instance, the results shown in Fig. 6 indicate a friction minimum at $0.9 \mathrm{~m} / \mathrm{min}$ where slag film has highest "stability".

Consequently, for the benefit of uniform solidification conditions particularly in case of "shrinkagesensitive" steels, mould powder selection should be optimized by aiming for a minimum heat fluxanalogous to the "soft cooling" - approach described already for mould cooling intensity. ${ }^{16)}$ In addition, mould friction measurements can be applied for further optimization.

\section{Steel Superheat}

While much has been said about the retarding

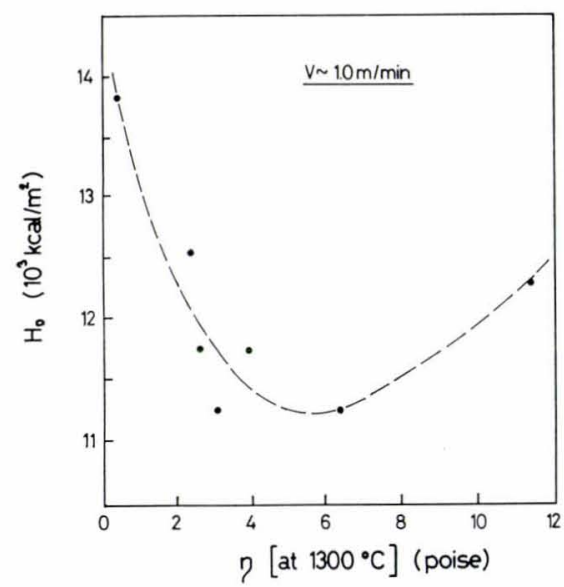

Fig. 5. Mould heat flux as function of mould powder viscosity (at $1300^{\circ} \mathrm{C}$ ) for carbon steel and $V=1.0 \mathrm{~m} /$ min, evaluated from Ref. 11). 


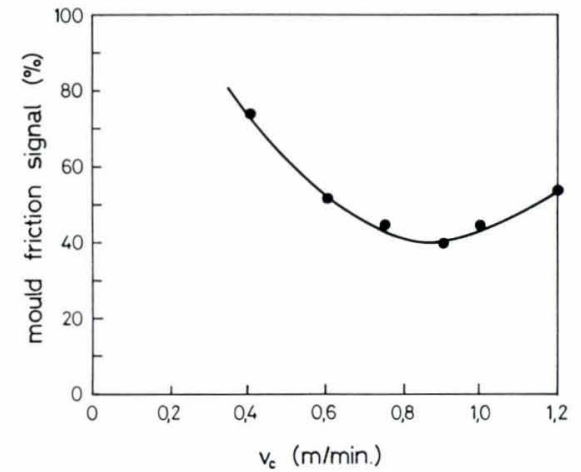

Fig. 6. Mould friction signal as function of casting speed for a given mould powder (viscosity at $1300^{\circ} \mathrm{C}$ about 6 poise), from Ref. 30).

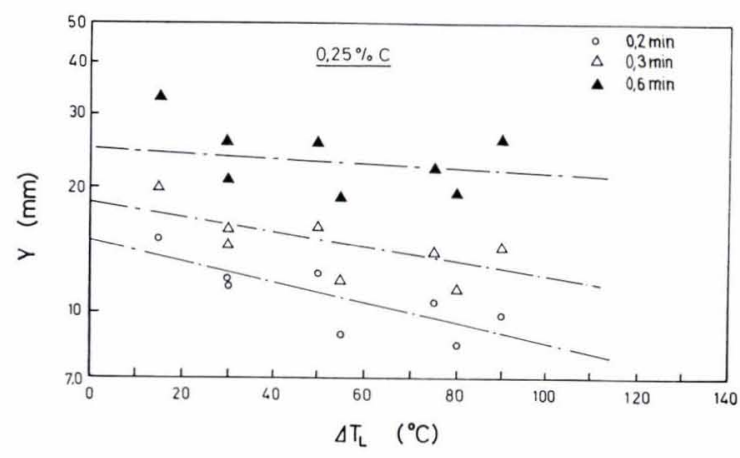

Fig. 7. Effect of steel superheat (measured in tundish) on shell thickness at mould exit as function of dwell time, evaluated from Ref. 33).

effect that superheat has on shell growth, little is known about the influence of superheat on heat flux, and the reported findings are few and controversial:

(1) In one case of a billet section $100 \times 100 \mathrm{~mm}$, a $10 \%$ increase of heat flux for $30^{\circ} \mathrm{C}$ was observed. ${ }^{9)}$

(2) In another observation of billet casting, for $50^{\circ} \mathrm{C}$ superheat only $3 \%$ increased heat flux was found. ${ }^{31 \text { ) }}$

(3) Whereas in further investigation of billet ${ }^{25}$ or slab ${ }^{11}$ casting, no change in heat flux was observed despite variation in superheat of $30^{\circ}$ to $40^{\circ} \mathrm{C}$.

Basically it has been assumed that, with increasing superheat, the thinner shell will give a better strand/ mould contact and hence improved heat flux. ${ }^{9)}$ However, depending on the type of convection prevailing in the mould, superheat in the mould may be dissipated either earlier or later. ${ }^{32}$ ) Upon this is superimposed the effect of casting speed, and the corresponding dwell time in the mould. For instance, the evaluation of the data ${ }^{33)}$ in Fig. 7 clearly shows that the superheat effect is especially prominent with short dwell times, i.e., high casting speeds. In such cases, it may well be that, with higher superheat, the resultingly thinner shell will lead to improved heat transfer as anticipated above. However, with $20^{\circ}$ to $40^{\circ} \mathrm{C}$ of superheat normally present, the effect on heat flux appears to be negligible.

\section{Steel Composition}

Perhaps the most disturbing factor in the interpre-

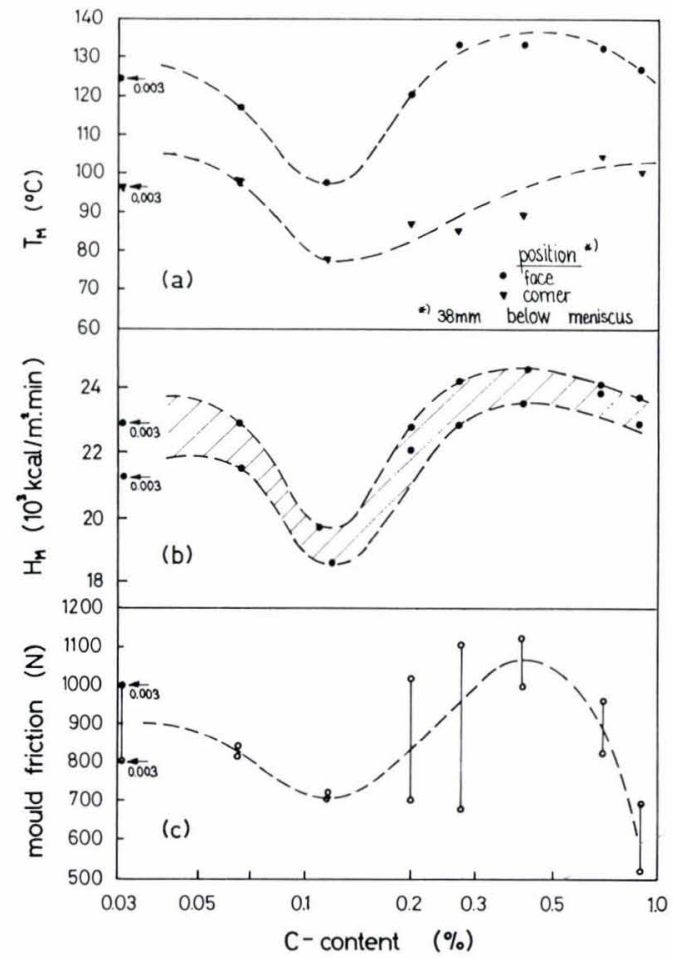

Fig. 8. Dependence of (a) mould wall temperature, (b) heat flux and (c) mould friction on carbon content, taken from Ref. 34).

tation of heat flux variation for a long time has been the effect of steel composition. It was observed earlier already $^{16)}$ that, for instance, the heat flux of $0.10 \% \mathrm{C}$ steel is about $20 \%$ below the heat flux for 0.20 to $0.25 \% \mathrm{C}$. Also it has been reported that higher $\mathrm{P}$ and S-contents increase heat flux. ${ }^{9)}$

However, only by systematic study of the effect of G-content ${ }^{34)}$ could it be shown that a very peculiar relationship exists with heat flux and steel composition due to changes in strand/mould contact. This has also been supported by the results of mould friction measurements (Fig. 8). Furthermore, a $0.3 \% \mathrm{~S}-\mathrm{ad}-$ dition to the $0.10 \% \mathrm{C}$-steel increased heat flux by $25 \%$ whereas in case of the $0.70 \% \mathrm{C}$-steel, heat flux remained unchanged. ${ }^{34)}$

These same authors ${ }^{34)}$ provided evidence which showed that the changes in heat flux as function of steel composition are directly related to the degree of "smoothness" or "roughness" of the strand surface. This is illustrated by the shell profiles, for instance, in case of the 0.10 and $0.70 \% \mathrm{C}$-steel in Fig. 9: the low carbon steel has a very wavy and uneven shell growth while the progress of shell growth for the high carbon steel is smooth and uniform. In both cases, the shell profile can be closely fitted to a parabolic time law, and comparison of the solidification constants, i.e., 18.3 and $29.7 \mathrm{~mm} / \mathrm{min}^{0.5}$ respectively, would indicate a difference in growth behaviour even larger $(40 \%)$ than indicated by the difference in heat flux $(25 \%)$. The difference in heat flux between high and low carbon steels largely disappears, however, in case of powder casting ${ }^{25)}$ as previously described under effects of mould lubricant. 


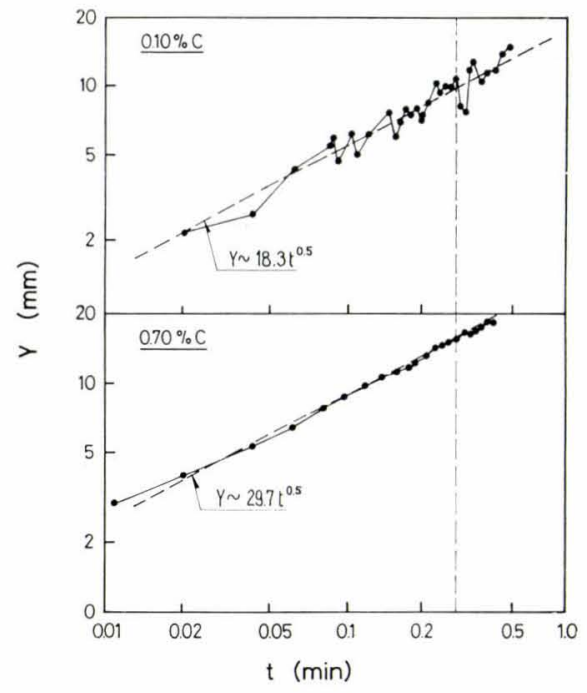

Fig. 9. Shell growth in the mould for two different steels, evaluated from Ref. 34).

\section{Discussion}

In order to reveal the effect that the various factors described above have on shell growth, a relationship between shell growth and heat flux must be established. Usually heat flux is defined in relation to mould surface area as shown, for instance, in Fig. 3. However, in view of its relationship with shell growth, heat flux per strand surface area seems to be a more appropriate expression. Such a definition was already suggested earlier ${ }^{21)}$ and, as one example, the values of $4000 \mathrm{kcal} / \mathrm{m}^{2}$ for $H_{0}$ and of $12000 \mathrm{kcal} / \mathrm{m}^{2}$. min for $H_{M}$ were correlated with a minimum shell thickness at mould exit of about $10 \mathrm{~mm}$. Since these expressions of heat flux are convertible by the simple relationship:

$$
H_{0}=H_{M} \cdot t_{M}
$$

the dwell time in the above example would amount to $0.33 \mathrm{~min}$, corresponding to the casting speed of $1.8 \mathrm{~m} / \mathrm{min}$ when assuming an active mould length of $0.6 \mathrm{~m}$. Furthermore, the constant of parabolic shell growth in this case results in $17.4 \mathrm{~mm} / \mathrm{min}^{0.5}$ and would correspond, in comparison with Fig. 7, to a low carbon steel around $0.10 \% \mathrm{C}$. The more general function given in Eq. (2) would, by use of Eq. (3), convert to

$$
H_{0} \sim 15000 t_{M}^{0.5}
$$

thus with the same numerical constant but in the opposite sense. For the example of $0.33 \mathrm{~min}$ dwell time, the $H_{0}$-value resulting from Eq. (4), in correspondence to Fig. 3 is $8617 \mathrm{kcal} / \mathrm{m}^{2}$, which may be indicative of higher carbon steels.

In order to relate shell thickness at mould exit to the heat flux per strand surface area, the following equation was suggested ${ }^{35}$ ) — not including the effect of steel superheat as a variable condition (compare Appendix):

$$
H_{0} \sim s \cdot \rho\left[0.5 \Delta E+c\left(T_{m}-\bar{T}_{0}\right)\right] \cdot 10^{3}
$$

Consequently, in Eq. (5), heat flux is the total of the
Table 3. Characteristic properties of steel near melting temperature. ${ }^{36,37)}$

\begin{tabular}{ccc}
\hline$\Delta E$ & $c_{S}$ & $\rho_{S}$ \\
\hline $62 \mathrm{cal} / \mathrm{g}$ & $0.17 \mathrm{cal} / \mathrm{g}^{\circ} \mathrm{C}$ & $7.4 \cdot 10^{-3} \mathrm{~g} / \mathrm{mm}^{3}$ \\
\hline
\end{tabular}

latent heat generated by shell growth up to mould exit plus the heat required to reduce the interface temperature to the average shell surface temperature. Applying this equation to the above example of $4000 \mathrm{kcal} / \mathrm{m}^{2}$ for $H_{0}$ and $10 \mathrm{~mm}$ for $Y_{m}$, and by the use of the characteristic data in Table 3 , a $\left(\mathcal{T}_{m}-\bar{T}_{0}\right)$ of $136^{\circ} \mathrm{C}$ would follow, and correspond to an average surface temperature of $1376^{\circ} \mathrm{C}$. This seems to be rather high but may be justified for a $0.10 \%$ C-steel with its irregular shell growth involving a large portion of strand surface termed "hot spots". 38 )

\section{Conclusion}

It seems, therefore, that by such a simplified approach mould heat flux data can be related to shell growth behaviour in a manner which allows the optimization and control of the continuous casting operation. This could be particularly important for the successful outcome of an operation based on " highspeed casting" where a sufficiently thick strand shell is needed at the mould exit.

Using heat flux to monitor the progress of shell growth in the mould, the effects of mould water velocity and steel superheat can be neglected under standard operating conditions. In the case of powder casting, the effect of mould lubricant might be held constant by an appropriate optimization of the slag properties as a function of the steel type and casting speed. In case of open casting, i.e., with oil lubrication, the strong dependence of mould heat flux on steel composition must be taken into account.

Based on such predetermined conditions, heat flux can be recorded as a function of the casting speed or dwell time in the mould. Any deviation toward values lower than expected might indicate a change in mould geometry, i.e., loss of mould taper in case of billet and bloom sections. Similarly, heat flux measurement could be used to optimize taper adjustment of the narrow faces. Thereby, additional information is obtainable from mould friction measurements.

In order to institute such a method of solidification control, it is necessary to substantiate the anticipated functions between mould heat flux and the various operating conditions by large-scale data evaluation. This has been attempted in a recent investigation on mould heat flux and shell growth. ${ }^{39)}$

\section{Nomenclature}

$C:$ constant in Eq. (1) (mm)

$c$ : specific heat $\left(\mathrm{cal} / \mathrm{g}^{\circ} \mathrm{C}\right)$

$E$ : enthalphy (cal $/ \mathrm{g})$

$F$ : slag film thickness $(\mathrm{mm})$

$f_{s}$ : solid fraction (-)

$H_{M}$ : heat flux per mould surface area $\left(\mathrm{kcal} / \mathrm{m}^{2} \mathrm{~min}\right)$

$H_{0}$ : heat flux per strand surface area $\left(\mathrm{kcal} / \mathrm{m}^{2}\right)$ 
$K$ : parabolic solidification constant $\left(\mathrm{mm} / \mathrm{min}^{0.5}\right)$

$P$ : mould powder consumption per strand surface area $\left(\mathrm{kg} / \mathrm{m}^{2}\right)$

$s: \quad$ shell thickness at mould exit (mm)

$T_{m}:$ temperature of shell interface $\cong\left(T_{L}+T_{S}\right) 0.5$ $\left({ }^{\circ} \mathrm{C}\right)$

$T_{0}:$ shell surface temperature $\left({ }^{\circ} \mathrm{G}\right)$

$t$ : solidification time ( $\mathrm{min})$

$t_{M}$ : dwell time in mould ( $\mathrm{min}$ )

$V:$ casting speed $(\mathrm{m} / \mathrm{min})$

$Y_{m}$ : shell thickness, i.e., distance of solid/liquid interface from strand surface ( $\mathrm{mm}$ )

$Z$ : distance from meniscus (m)

$\eta$ : viscosity of slag film (poise)

$\rho:$ density $\left(\mathrm{g} / \mathrm{mm}^{3}\right)$

\section{REFERENCES}

1) K. Heck and H. Fastert: Iron Steel Eng., (1973), No. 2, 33.

2) W. Kurz: Proc. 5th Internat. Conf. Vacuum Metall. and ESR, Munich, (1976), 5.

3) H. Krainer and B. Tarmann: Stahl u. Eisen, 69 (1949), 813.

4) J. Savage and W. H. Pritchard: JISI, 178 (1954), 269.

5) E. A. Mizikar: Proc. Ann. Meeting AIME, Los Angeles, (1967).

6) K. A. Fekete: Berg- u. Hüttenm. Mh., 114 (1969), 19.

7) H. Jones: J. Inst. Metals, 97 (1969), 38.

8) S. K. Morton and F. Weinberg: JISI, 211 (1973), 13.

9) P. J. Koenig: Stahl u. Eisen, 92 (1972), 678.

10) J. E. Lait, J. K. Brimacombe and F. Weinberg: Proc. Ann. Meeting AIME, Chicago, (1973).

11) R. Alberny, A. Leclercq, D. Amaury and M. Lahousse: C.I.T., (1976), No. 11, 2469-2491.

12) H. Marti and J. Barbé: Rév. Met., 5 (1976), 457.

13) H. Jacobi: "Casting and Solidification of Steel ", EUR 5861, Luxembourg, (1977).

14) W. R. Irving: Comm. by British Steel Corp., Teesside Laboratories, 1976.

15) E. Bachner and M. Ussar: Stahl u. Eisen, 96 (1976), 185.

16) C. Holden, J. W. Menter and D. Vincent: JISI, Sept. (1966), 887.

17) T. Onaka: Comm. by Sumitomo Metal Industries, Ltd., Osaka, 1961.

18) E. L. Fogleman and R. T. Orie: J. Metals, (1974), No. 10, 37.

19) Y. Sato and S. Kato: Comm. by Nippon Yakin Kogyo, Co. Ltd., 1975.

20) K. Ushijima: Tetsu-to-Hagané, 48 (1962), 845.

21) B. Tarmann and O. Kleinhagauer: Stahl u. Eisen, 81 (1961), 111.

22) B. Tarmann: Radex Rdsch., (1971), 591.

23) K. Saito and M. Tate: OH-Proc. AIME, Cleveland, (1973), 238.

24) D. P. Evteev: Stal in Engl., (1969), No. 8, 708.

25) S. N. Singh and K. E. Blazek: Proc. Nat. O-H Comm. AIME, St. Louis, (1976), 264.

26) P. J. Koenig: Comm. by Prodanor AG, 1972.

27) S. Miyoshi, M. Itoh and I. Nishi: Comm. by Nippon Kokan K.K., Fukuyama, 1972.

28) T. Emi, K. Emoto, T. Imai, H. Moriwaki, Y. Habu, R. Tachibana and H. Nakato: Comm. by Kawasaki Steel Corp., 1976.

29) A. Hettler and P. Potier: C.I.T. No. 12, (1978), 2149 2160 .

30) B. Mairy, D. Ramelot and P. Dauby: Stahl u. Eisen, 99 (1979), 737.
31) K. Ushijima: Iron Steel Inst. Spec. Rep., 89 (1965), 59.

32) S. Asai and J. Szekely: Ironmaking Steelmaking, (Quart.) (1975), 205.

33) B. Tarmann and G. Forstner: Radex Rundsch., (1966), 51.

34) S. N. Singh and K. E. Blazek: J. Metals, 26 (1974), No. $10,17$.

35) G. Vogt and K. Wünnenberg: Klepzig Fachber., 80 (1972), 491.

36) F. Richter: Sonderber, Nr. 8, Verlag Stahleisen, Düsseldorf, 1973.

37) C. J. Smithells: Metals Reference Book, 5th Ed., Butterworths, London, (1976).

38) A. Grill, K. Sorimachi and J. K. Brimacombe: Met. Trans., 7B (1976), 177.

39) M. Wolf: Trans. ISIJ, 20 (1980), 710.

\section{Appendix}

In an earlier study, ${ }^{1)}$ mould heat flux has been connected with shell growth up to mould exit by simply adding the latent heat generated during growth and the heat necessary to reduce the temperature of the solid/liquid interface down to an average shell surface temperature. Accordingly, this approach was taken also in the present investigation and the resultant function

$$
H_{0} \sim s \cdot \rho\left[0.5 \Delta E+c\left(\mathcal{T}_{m}-\bar{T}_{0}\right)\right] \cdot 10^{3}
$$

based on the following considerations.

\section{Enthalpy of Shell Formation}

Without superheat of the liquid shell, shell growth would follow the parabolic growth function shown in Fig. A-1. With increasing superheat, initial shell growth is retarded, which could be described by a series of different parabolic solidification constants $K$ gradually increasing from low to normal values. ${ }^{2,3}$ ) This may be more conveniently expressed by a fitted function of the type $Y \sim K^{\prime} t^{\mathrm{n}}$. At large superheats, the growth exponent $n$ approaches unity corresponding to linear shell growth ${ }^{4}$ which is also indicated in Fig. A-1. With the usually applied superheat between $20^{\circ}$ and $40^{\circ} \mathrm{C}$, the growth function would fall somewhere between the curves in Fig. A-1, and the en-

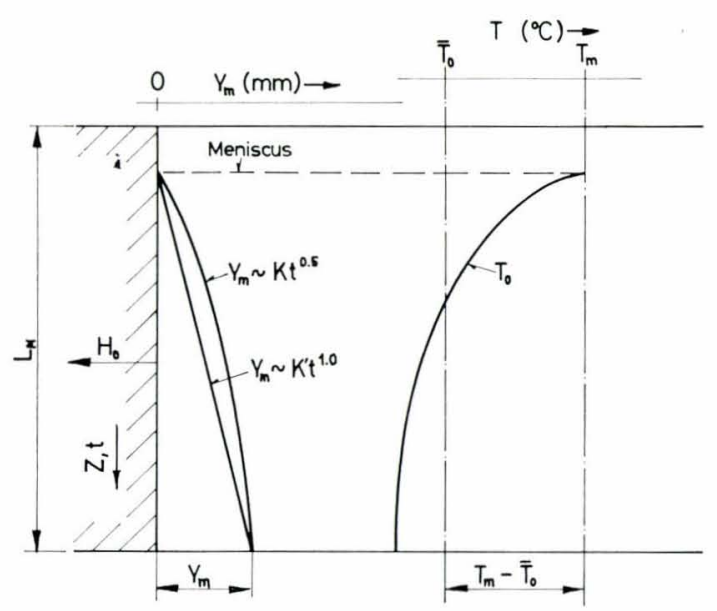

Fig. A-1. Schematic presentation for the courses of shell growth and strand surface temperature in the mould. 
thalpy part of the mould heat flux is to be calculated accordingly by integration of the corresponding growth function between meniscus and mould exit. But in the present model, shell thickness at mould exit is derived from the application of the parabolic solidification constant (i.e., " no superheat"-condition), which may give slightly higher values than the real case, but provides convenience in the calculation. On the other hand, the linear growth curve (i.e., " high superheat ") is applied at the same time, which allows to express the enthalpy portion of heat flux simply by a $0.5 \Delta E$-term. This results in a somewhat too-low heat flux and, thus, may compensate the effect of the larger shell thickness resulting from the parabolic solidification constant.

\section{Temperature Difference in the Strand Shell}

The assumed temperature difference between the solid/liquid interface $T_{m}$ and the shell surface temperature $T_{0}$ increases rapidly during the initial stage of shell formation, then only slightly. If shell growth is based on the parabolic solidification constant $K$, the assumption of a constant shell surface temperature would lead to an average difference $\bar{\Delta}\left(\mathcal{T}_{m}-\mathcal{T}_{0}\right)$ as shown by the curves on the right-hand side of Fig. A-1. Such a relationship between $K$ and $T_{m}-T_{0}$ has been discussed previously ${ }^{2}$ and is applied in the present model too. Despite the variation of the actual shell surface temperature, this simplified approach may be quite satisfactory for the order of magnitude estimation intended here.

\section{REFERENCES}

1) A. Vogt and K. Wünnenberg: Klepzig Fachber., 80 (1972), 491.

2) M. Wolf and W. Kurz: Solidification and Casting of Metals, The Metals Society, London, (1979), 287-294.

3) R. Alberny: Casting and Solidification of Steel, ECSC, Luxembourg, (1977), 278-335.

4) B. Tarmann and G. Forstner: Radex Rdsch. (1966), 51. 